\title{
Corticosteroid therapy in patients with heart failure hospitalized for COVID-19: a multicenter retrospective study
}

\author{
Luis M. Pérez-Belmonte ${ }^{1}$. Jaime Sanz-Cánovas ${ }^{1} \cdot$ Alejandro Salinas $^{2} \cdot$ Iñigo Sagastagoitia Fornie $^{2}$. \\ Manuel Méndez-Bailón ${ }^{2} \cdot$ Ricardo Gómez-Huelgas ${ }^{1}$ on behalf of the SEMI-COVID-19 Network
}

Received: 6 June 2021 / Accepted: 7 September 2021 / Published online: 12 October 2021

(c) Società Italiana di Medicina Interna (SIMI) 2021

\section{Dear Editor:}

The efficacy of corticosteroid use in COVID-19 has been widely debated [1]. Although corticosteroids were found to be associated with improved clinical outcomes in severely ill patients in a recent systematic review and meta-analysis of randomized clinical trials, the sequential analysis suggested a need for further research to confirm these results [2].

Among patients hospitalized with COVID-19, the presence of heart failure (HF) has been reported as a potential risk factor for worse outcomes [3]. However, limited data are available on the clinical profile and therapeutic approach in this subgroup of patients [3, 4]. Indeed, there is little evidence on the use of systemic corticosteroids in HF in general. A high dose of corticosteroids may promote sodium and water retention in patients with HF, potentially leading to worsening of the disease [4]. The risks and benefits of systemic corticosteroids must be carefully weighed according to HF guidelines $[4,5]$. In this work, our main objective was to evaluate the association between in-hospital deaths and corticosteroids therapy in patients with HF hospitalized due to COVID-19. We also evaluated their association with

Manuel Méndez-Bailón and Ricardo Gómez-Huelgas have contributed equally and share the last authorship

Luis M. Pérez-Belmonte

luismiguelpb1984@gmail.com

$\bowtie$ Alejandro Salinas

asalinasbotran@yahoo.es

1 Internal Medicine Department, Regional University Hospital of Málaga, Biomedical Research Institute of Málaga (IBIMA), University of Málaga (UMA), Avenida de Carlos Haya, s/n, 29010 Málaga, Spain

2 Internal Medicine Department, Hospital Clínico San Carlos, Universidad Complutense de Madrid, Instituto de Investigación Sanitaria del Hospital Clínico San Carlos (IdISSC), Calle del Profesor Martín Lagos, s/n, 28040 Madrid, Spain the presence of acute decompensated HF (ADHF), need for mechanical ventilation, and in-hospital complications.

We selected all patients with a known history of HF included in the SEMI-COVID-19 Registry from March to December 2020. This Registry is an ongoing, nationwide cohort of $\geq 18$-year-old patients admitted for COVID-19 confirmed by positive real-time reverse transcription-polymerase chain reaction test in Spain. In brief, it retrospectively compiles sociodemographic variables, comorbidities, preadmission treatment, clinical presentation, laboratory data, hospital complications, hospital stay, and in-hospital death from the first admission for COVID-19 [6]. All information contained in the database, the configuration of the information within the database, as well as the database itself are fully encrypted, and daily backups are performed in order to ensure data integrity.

Manual review was performed for patients identified as having a history of HF by International Classification of Disease-9th and/or 10th. The degree of functional dependence and the presence of comorbidities was assessed using the Barthel Index and Charlson Comorbidity Index, respectively.

In-hospital complications include the onset of at least one of the following: secondary bacterial pneumonia; acute respiratory distress syndrome; ADHF; arrhythmia; acute coronary syndrome; myocarditis; epileptic seizures; stroke; shock; sepsis; acute kidney failure; disseminated intravascular coagulation; venous thromboembolism; multiple organ dysfunction syndrome; acute limb ischemia; intensive care unit (ICU) admission; and need for ventilation support, including invasive and noninvasive mechanical ventilation or high-flow oxygen therapy.

The severity grade of COVID-19 disease was established according to the patient's clinical condition: moderate grade (clinical signs of pneumonia but not signs of severe pneumonia, including basal oxygen saturation $\geq 92 \%$ ), severe grade (clinical signs of pneumonia plus one of the following: basal oxygen saturation $<92 \%$; 
resting respiratory rate $>30$ breaths/minute; severe respiratory distress), and critical grade (sepsis or shock with acute respiratory distress syndrome and/or multiple organ dysfunction or failure).

The primary outcome was in-hospital death according to corticosteroids use. Secondary outcomes included (1) presence of ADHF, (2) need for invasive and noninvasive mechanical ventilation, and (3) in-hospital complications.

Categorical and continuous variables were expressed as absolute value and percentages and as means \pm standard deviation, respectively. Differences between groups were determined using Pearson's Chi-squared test for categorical variables and the two-sample Student's $t$ test or Mann-Whitney-Wilcoxon $U$ test for continuous variables.

To match a patient in one group with a patient in another in a 1:1 manner, propensity scores using nearest neighbour matching with a caliper of 0.1 and a greedy matching algorithm were used. Logistic regression was used to determine the probability of having corticosteroid therapy and included variables that could have affected outcomes as independent variables (age, sex, comorbidities, preadmission treatment, clinical presentation, laboratory data, and in-hospital treatment). Standardized mean differences were calculated to evaluate the adequacy of propensity matching. To estimate the association between treatment and study outcomes, both conditional logit and mixed effect (matched pairs as random effects) logistic regression models were used. Statistical analyses were performed using R software, version 3.6.2.

Of the 1155 patients with HF in the cohort, 477 were treated with corticosteroids (406 with $68.0 \pm 20.5 \mathrm{mg}$ of intravenous methylprednisolone daily during $6.0 \pm 3.3$ days, 48 with $16.5 \pm 5.2 \mathrm{mg}$ of intravenous dexamethasone daily during $5.8 \pm 3.1$ days, and 23 with other regimens). After propensity matching, 298 patients were included in each group. All clinical and treatment characteristics were wellbalanced and no significant differences were noted. The data on clinical characteristics, management, and outcomes according to corticosteroid treatment both before and after the propensity matching analysis are summarized in Table 1.

With regard to study outcomes, corticosteroid therapy was associated with higher rates of in-hospital death, ADHF, need for invasive and noninvasive mechanical ventilation, and in-hospital complications (Table 2).

Numerous interventional and noninterventional studies are currently being conducted to evaluate the efficacy of corticosteroids in COVID-19 [1, 2]. Corticosteroids could play a role in suppressing lung inflammation and inhibiting immune responses [1]. Recently, a meta-analysis of seven randomized clinical trials with a total of 6250 patients with moderate to severe COVID-19 indicated that corticosteroids therapy was associated with reductions in mortality and disease progression [2]. The effect of corticosteroids seems to depend on the disease severity. Their use may be appropriate in severe forms of COVID-19, but discouraged in patients who do not require ventilation support [7].

Despite these data, there is certainty a dearth of evidence on this matter at present. The great degree of heterogeneity among studies in aspects such as the definition of disease severity, type and dose of corticosteroids evaluated, concomitant treatments used, and outcomes explored make further investigation necessary [2, 7]. In our study, patients with HF hospitalized due to COVID-19 who received corticosteroids therapy had higher rates of in-hospital mortality, HF decompensation, need of ventilation support, and in-hospital complications. The largest randomized clinical trial evaluating the effect of corticosteroid therapy in COVID-19 published to date is the RECOVERY trial [8]. In this report, patients in the corticosteroid group were 11.6 years old younger than those in our study and had fewer comorbidities. These factors could underlie the increased mortality observed in the group treated with corticosteroids in our study as compared to what found in the RECOVERY trial (49.7\% vs $22.9 \%)$. Corticosteroids therapy, and particularly those with mineralocorticoid action, may have adverse impact on HF patients, potentially leading to ADHF $[4,5]$. The evaluation of risks and benefits in various patient subgroups at particular risk for complications, such as patients with HF, could potentially lead to more benefits than risks when using this type of treatment.

In regard to HF treatment during hospitalization, our registry only recorded the use of renin-angiotensin-aldosterone system (RAAS) inhibitors. The impact of cardiovascular drugs on the clinical course of COVID-19 has not yet been determined. The recent studies indicate treatment with renin-angiotensin-aldosterone system inhibitors could be beneficial $[9,10]$. There is limited evidence on the effect of RAASi in patients with HF hospitalized for COVID-19 and all studies focus on the clinical implications of HF on the course of COVID-19 rather than HF treatment [3, 11, 12]. The relationship between $\beta$-blockers and adverse outcomes in COVID-19 remains unknown. It has been hypothesized that $\beta$-blockers could reduce host cell entry by the virus and reduce the catecholamine-dependent inflammatory over response [13]. Recently, an observational study on hospitalized patients with COVID-19 found that the use of RAAS inhibitors and $\beta$-blockers was associated with lower mortality [14]. Further research is needed to confirm the impact of HF treatments on COVID-19 patients.

To the best of our knowledge, this is the first large study that examines the association between corticosteroid therapy and adverse outcomes in patients with HF and COVID-19 that includes a robust adjustment made for many confounding variables. Nevertheless, several potential limitations of this work must be considered. First, the possibility of unmeasured confounding factors cannot be ruled out due to the study's retrospective nature. Second, our registry did not 
Table 1 Baseline clinical characteristics, management, and outcomes of patients with history of heart failure admitted for COVID-19 according to corticosteroid therapy use: pre- and postpropensity matching analysis

\begin{tabular}{|c|c|c|c|c|c|c|c|c|}
\hline & \multicolumn{4}{|c|}{ Prepropensity matching analysis } & \multicolumn{4}{|c|}{ Postpropensity matching analysis } \\
\hline & $\begin{array}{l}\text { Corticosteroids } \\
(n=477)\end{array}$ & $\begin{array}{l}\text { No corticosteroids } \\
(n=678)\end{array}$ & $p$ value & SMD & $\begin{array}{l}\text { Corticosteroids } \\
(n=298)\end{array}$ & $\begin{array}{l}\text { No corticosteroids } \\
(n=298)\end{array}$ & $p$ value & SMD \\
\hline Age (years) & $79.9 \pm 10.3$ & $77.8 \pm 10.0$ & 0.094 & 0.091 & $78.5 \pm 10.1$ & $78.0 \pm 10.0$ & 0.378 & 0.014 \\
\hline Male gender & $260(54.5 \%)$ & $340(50.1 \%)$ & 0.112 & 0.098 & $157(52.7 \%)$ & $150(50.3 \%)$ & 0.317 & 0.017 \\
\hline \multicolumn{9}{|l|}{ Comorbidities } \\
\hline History of smoking & $215(45.1 \%)$ & $270(39.8 \%)$ & 0.028 & 0.128 & $130(43.6 \%)$ & $122(40.9 \%)$ & 0.258 & 0.029 \\
\hline Obesity & $188(39.4 \%)$ & $208(30.7 \%)$ & 0.040 & 0.115 & $107(35.9 \%)$ & $101(33.9 \%)$ & 0.280 & 0.021 \\
\hline Diabetes mellitus & $180(37.7 \%)$ & $261(38.5 \%)$ & 0.412 & 0.010 & $113(37.9 \%)$ & $114(38.3 \%)$ & 0.455 & 0.007 \\
\hline Hypertension & $429(89.9 \%)$ & $624(92.0 \%)$ & 0.299 & 0.028 & $268(89.9 \%)$ & $271(90.9 \%)$ & 0.319 & 0.018 \\
\hline Dyslipidemia & $287(60.2 \%)$ & $441(65.0 \%)$ & 0.119 & 0.088 & $185(62.1 \%)$ & $190(63.8 \%)$ & 0.294 & 0.027 \\
\hline $\begin{array}{l}\text { Chronic kidney } \\
\text { disease }\end{array}$ & $104(21.8 \%)$ & $156(23.0 \%)$ & 0.401 & 0.012 & $65(21.8 \%)$ & $68(22.8 \%)$ & 0.487 & 0.005 \\
\hline Atrial fibrillation & $215(45.1 \%)$ & $320(47.2 \%)$ & 0.331 & 0.041 & $135(45.3 \%)$ & $140(47.0 \%)$ & 0.357 & 0.030 \\
\hline $\begin{array}{l}\text { Coronary artery } \\
\text { disease }\end{array}$ & $215(45.1 \%)$ & $322(47.5 \%)$ & 0.274 & 0.057 & $137(46.0 \%)$ & $140(47.0 \%)$ & 0.301 & 0.036 \\
\hline $\begin{array}{l}\text { Chronic obstruc- } \\
\text { tive pulmonary } \\
\text { disease }\end{array}$ & $115(24.1 \%)$ & $121(17.8 \%)$ & 0.022 & 0.158 & $60(20.1 \%)$ & $55(18.5 \%)$ & 0.211 & 0.058 \\
\hline Stroke & $33(6.9 \%)$ & $48(7.1 \%)$ & 0.378 & 0.028 & $21(7.0 \%)$ & $21(7.0 \%)$ & 0.495 & 0.007 \\
\hline Dementia & $67(14.0 \%)$ & $122(18.0 \%)$ & 0.073 & 0.083 & $45(15.1 \%)$ & $50(16.8 \%)$ & 0.193 & 0.070 \\
\hline $\begin{array}{l}\text { Moderate-severe } \\
\text { functional } \\
\text { dependence }\end{array}$ & $157(32.9 \%)$ & $258(38.1 \%)$ & 0.043 & 0.124 & $104(34.9 \%)$ & $110(36.9 \%)$ & 0.214 & 0.059 \\
\hline $\begin{array}{l}\text { Moderate-severe } \\
\text { comorbidity }\end{array}$ & $467(97.9 \%)$ & $665(98.1 \%)$ & 0.455 & 0.009 & $292(98.0 \%)$ & $292(98.0 \%)$ & 0.489 & 0.007 \\
\hline Disease severity & & & 0.022 & 0.166 & & & 0.176 & 0.086 \\
\hline Moderate & $272(57.0 \%)$ & $508(74.9 \%)$ & & & $197(66.1 \%)$ & $212(71.1 \%)$ & & \\
\hline Severe & $167(35.0 \%)$ & $170(25.1 \%)$ & & & $89(29.9 \%)$ & $86(28.9 \%)$ & & \\
\hline Critical & $38(8.0 \%)$ & $0(0.0 \%)$ & & & $12(4.0 \%)$ & $0(0.0 \%)$ & & \\
\hline \multicolumn{9}{|l|}{ Laboratory data } \\
\hline $\begin{array}{l}\text { Blood glucose, } \\
\mathrm{mg} / \mathrm{dL}\end{array}$ & $154.3 \pm 55.2$ & $141.0 \pm 44.2$ & 0.030 & 0.132 & $145.3 \pm 47.3$ & $143.1 \pm 44.7$ & 0.475 & 0.005 \\
\hline Creatinine, $\mathrm{md} / \mathrm{dL}$ & $1.6 \pm 1.5$ & $1.6 \pm 1.3$ & 0.466 & 0.006 & $1.6 \pm 1.5$ & $1.6 \pm 1.3$ & 0.497 & 0.004 \\
\hline $\begin{array}{l}\text { Dehydrogenase } \\
\text { lactate, U/L }\end{array}$ & $404.9 \pm 203.1$ & $311.0 \pm 153.7$ & 0.040 & 0.119 & $354.2 \pm 173.2$ & $333.1 \pm 160.1$ & 0.244 & 0.019 \\
\hline Ferritin, $\mathrm{mcg} / \mathrm{L}$ & $995.1 \pm 513.3$ & $544.8 \pm 330.2$ & 0.019 & 0.197 & $695.2 \pm 374.2$ & $599.8 \pm 341.0$ & 0.208 & 0.027 \\
\hline $\begin{array}{l}\text { Interleukin-6,pg/ } \\
\mathrm{mL}\end{array}$ & $90.6 \pm 35.8$ & $39.2 \pm 25.9$ & 0.020 & 0.184 & $70.1 \pm 30.1$ & $61.0 \pm 29.9$ & 0.268 & 0.018 \\
\hline $\begin{array}{l}\text { C-reactive protein, } \\
\text { mg/L }\end{array}$ & $98.2 \pm 57.6$ & $41.4 \pm 46.2$ & 0.031 & 0.129 & $71.0 \pm 50.0$ & $63.2 \pm 47.1$ & 0.237 & 0.014 \\
\hline D-Dimer, ng/ml & $1779.8 \pm 1289.3$ & $1234.1 \pm 1106.1$ & 0.040 & 0.120 & $1529.0 \pm 1195.2$ & $1399.2 \pm 1156.4$ & 0.241 & 0.012 \\
\hline \multicolumn{9}{|l|}{ In-hospital treatment } \\
\hline RAAS inhibitors & $250(52.4 \%)$ & $406(59.9 \%)$ & 0.103 & 0.091 & $164(55.0 \%)$ & $170(57.0 \%)$ & 0.202 & 0.041 \\
\hline $\begin{array}{l}\text { Hydroxychloro- } \\
\text { quine/chloro- } \\
\text { quine }\end{array}$ & $372(78.0 \%)$ & $509(75.1 \%)$ & 0.198 & 0.079 & $229(76.8 \%)$ & $226(75.8 \%)$ & 0.244 & 0.052 \\
\hline Lopinavir/ritonavir & $200(41.9 \%)$ & $238(35.1 \%)$ & 0.168 & 0.091 & $110(36.9 \%)$ & $108(36.2 \%)$ & 0.301 & 0.038 \\
\hline Azithromycin & $241(50.5 \%)$ & $332(49.0 \%)$ & 0.207 & 0.059 & $149(50.0 \%)$ & $148(49.7 \%)$ & 0.499 & 0.011 \\
\hline Remdesivir & $10(2.1 \%)$ & $7(1.0 \%)$ & 0.213 & 0.088 & $5(1.7 \%)$ & $4(1.3 \%)$ & 0.258 & 0.075 \\
\hline Interferon- $\beta$ & $57(11.9 \%)$ & $67(9.9 \%)$ & 0.149 & 0.092 & $32(10.7 \%)$ & $30(10.1 \%)$ & 0.302 & 0.058 \\
\hline Tocilizumab & $59(12.4 \%)$ & $55(8.1 \%)$ & 0.101 & 0.096 & $30(10.1 \%)$ & $28(9.3 \%)$ & 0.224 & 0.069 \\
\hline
\end{tabular}


Table 1 (continued)

\begin{tabular}{|c|c|c|c|c|c|c|c|c|}
\hline & \multicolumn{4}{|c|}{ Prepropensity matching analysis } & \multicolumn{4}{|c|}{ Postpropensity matching analysis } \\
\hline & $\begin{array}{l}\text { Corticosteroids } \\
(n=477)\end{array}$ & $\begin{array}{l}\text { No corticosteroids } \\
(n=678)\end{array}$ & $p$ value & SMD & $\begin{array}{l}\text { Corticosteroids } \\
(n=298)\end{array}$ & $\begin{array}{l}\text { No corticosteroids } \\
(n=298)\end{array}$ & $p$ value & SMD \\
\hline \multicolumn{9}{|l|}{ Outcomes } \\
\hline In-hospital deaths & $239(50.1 \%)$ & $286(42.2 \%)$ & 0.005 & 0.199 & $148(49.7 \%)$ & $129(43.3 \%)$ & 0.039 & 0.149 \\
\hline $\begin{array}{l}\text { Acute heart failure } \\
\text { decompensation }\end{array}$ & $210(44.0 \%)$ & $178(26.3 \%)$ & 0.002 & 0.214 & $119(39.9 \%)$ & $90(30.2 \%)$ & 0.012 & 0.199 \\
\hline $\begin{array}{l}\text { Mechanical venti- } \\
\text { lation }\end{array}$ & $97(20.3 \%)$ & $81(11.9 \%)$ & 0.021 & 0.129 & $50(16.8 \%)$ & $36(12.1 \%)$ & 0.044 & 0.107 \\
\hline $\begin{array}{l}\text { In-hospital compli- } \\
\text { cations }\end{array}$ & $285(59.7 \%)$ & $241(35.5 \%)$ & $<0.001$ & 0.254 & $149(50.0 \%)$ & $113(37.9 \%)$ & 0.002 & 0.217 \\
\hline
\end{tabular}

Data are shown as mean \pm standard deviations, absolute values, and percentages. Values were considered to be statistically significant when $p<0.05$

$R A A S$ renin-angiotensin-aldosterone system

Table 2 Association between corticosteroid therapy and study outcomes

\begin{tabular}{|c|c|c|c|c|}
\hline \multirow[t]{3}{*}{ Outcomes } & \multicolumn{4}{|c|}{ Corticosteroid therapy use } \\
\hline & \multicolumn{2}{|c|}{$\begin{array}{l}\text { Conditional logit logistic regres- } \\
\text { sion }\end{array}$} & \multicolumn{2}{|c|}{$\begin{array}{l}\text { Mixed effect logistic regres- } \\
\text { sion }\end{array}$} \\
\hline & OR $(95 \% \mathrm{CI})$ & $p$ value & OR $(95 \% \mathrm{CI})$ & $p$ value \\
\hline In-hospital death & $1.39(1.08-1.90)$ & 0.040 & $1.38(1.08-1.92)$ & 0.040 \\
\hline Acute heart failure decompensation & $1.67(1.09-2.27)$ & 0.021 & $1.67(1.08-2.29)$ & 0.022 \\
\hline Mechanical ventilation & $1.15(1.01-1.99)$ & 0.044 & $1.16(1.01-1.99)$ & 0.044 \\
\hline In-hospital complications & $1.92(1.11-2.91)$ & 0.012 & $1.91(1.10-2.92)$ & 0.012 \\
\hline
\end{tabular}

Values were considered to be statistically significant when $p<0.05$

OR odd ratio, $95 \%$ CI $95 \%$ confidence interval record HF characteristics, such as the principal cause of HF, New York Heart Association functional class, left ventricular ejection fraction, natriuretic peptide levels, and or HF treatment. Third, no other adverse intermediate outcomes could be evaluated because of the low number of instances. Fourth, due to the fact that most patients were treated with methylprednisolone, we cannot determine the differences among the various types of corticosteroids. Lastly, corticosteroid therapy varied in both dose and duration due to treatment regimens were not predefined among hospitals.

In conclusion, our study found that the corticosteroid therapy was associated with a higher rate of in-hospital death and other adverse outcomes in patients with HF hospitalized due to COVID-19. Given the disparity in the evidence on the role of corticosteroid therapy in COVID-19 patients, high-quality randomized clinical trials are urgently needed, especially those designed to evaluate the efficacy and safety of these drugs in patients at high risk of complications.

Funding This research received no specific grant from any funding agency in the public, commercial or not-for-profit sectors.
Data availability Further data will be provided on request.

\section{Declarations}

Conflict of interest The authors declare that they have no conflict of interest.

Ethics approval This study was approved by the Institutional Research Ethics Committee of Málaga on March 27, 2020 (Ethics Committee code: SEMI-COVID-19 27-03-20).

Statement of human and animal rights This was conducted pursuant to the Declaration of Helsinki.

Consent to participate Only patients who had previously given consent for their data to be used for medical research were included in this study. Patient identifying information was deleted before the database was analyzed and it is not possible to identify patients on an individual level either in this article or in the database.

\section{References}

1. Shang L, Zhao J, Hu Y, Du R, Cao B (2020) On the use of corticosteroids for 2019-nCoV pneumonia. Lancet 395(10225):683684. https://doi.org/10.1016/S0140-6736(20)30361-5 
2. Ma S, Xu C, Liu S et al (2021) Efficacy and safety of systematic corticosteroids among severe COVID-19 patients: a systematic review and meta-analysis of randomized controlled trials. Signal Transduct Target Ther 6(1):83. https://doi.org/10.1038/ s41392-021-00521-7

3. Alvarez-Garcia J, Lee S, Gupta A et al (2020) Prognostic impact of prior heart failure in patients hospitalized with COVID-19. J Am Coll Cardiol 76(20):2334-2348. https://doi.org/10.1016/j. jacc.2020.09.549

4. Zhang Y, Coats AJS, Zheng Z et al (2020) Management of heart failure patients with COVID-19: a joint position paper of the Chinese Heart Failure Association and National Heart Failure Committee and the Heart Failure Association of the European Society of Cardiology. Eur J Heart Fail 22(6):941-956. https://doi.org/10. 1002/ejhf.1915

5. Ponikowski P, Voors AA, Anker SD et al (2016) 2016 ESC Guidelines for the diagnosis and treatment of acute and chronic heart failure: the Task Force for the diagnosis and treatment of acute and chronic heart failure of the European Society of Cardiology (ESC). Developed with the special contribution of the Heart Failure Association (HFA) of the ESC. Eur J Heart Fail 18(8):891975. https://doi.org/10.1002/ejhf.592

6. Casas Rojo JM, Antón Santos JM, Millán Núñez-Cortés J et al (2020) Clinical characteristics of patients hospitalized with COVID-19 in Spain: results from the SEMI-COVID-19 Registry. Rev Clin Esp 220(8):480-494. https://doi.org/10.1016/j.rceng. 2020.07.003

7. Pasin L, Navalesi P, Zangrillo A et al (2021) Corticosteroids for patients with coronavirus disease 2019 (COVID-19) with different disease severity: a meta-analysis of randomized clinical trials. J Cardiothorac Vasc Anesth 35(2):578-584. https://doi.org/ 10.1053/j.jvca.2020.11.057

8. Horby P, Lim WS, Emberson JR et al (2021) Dexamethasone in hospitalized patients with COVID-19. N Engl J Med 384(8):693704. https://doi.org/10.1056/NEJMoa2021436
9. Chatrath N, Kaza N, Pabari PA et al (2020) The effect of concomitant COVID-19 infection on outcomes in patients hospitalized with heart failure. ESC Heart Fail 7(6):4443-4447. https://doi. org/10.1002/ehf2.13059

10. Yokiyama Y, Aikawa T, Takagi H et al (2020) Association of renin-angiotensin-aldosterone system inhibitors with mortality and testing positive of COVID-19: meta-analysis. J Med Virol 93(4):2084-2089. https://doi.org/10.1002/jmv.26588

11. Inciardi RM, Adamo M, Lupi L et al (2020) Characteristics and outcomes of patients hospitalized for COVID-19 and cardiac disease in Northern Italy. Eur Heart J 41(19):1821-1829. https://doi. org/10.1093/eurheartj/ehaa388

12. Sardu C, Maggi P, Messina V et al (2020) Could anti-hypertensive drug therapy affect the clinical prognosis of hypertensive patients with COVID-19 infection? Data from centers of southern Italy. J Am Heart Assoc 9(17):e016948. https://doi.org/10.1161/JAHA. 120.016948

13. Vasanthakumar N (2020) Beta-adrenergic blockers as a potential treatment for COVID-19 patients. BioEssays 42(11):e2000094. https://doi.org/10.1002/bies.202000094

14. Terlecki M, Wojciechowska W, Klocek M et al (2021) Association between cardiovascular disease, cardiovascular drug therapy, and in-hospital outcomes in patients with COVID-19: data from a large single-center registry in Poland. Kardiol Pol. https://doi. org/10.33963/KP.15990

Publisher's Note Springer Nature remains neutral with regard to jurisdictional claims in published maps and institutional affiliations. 